\title{
A family with a high incidence of juvenile rheumatoid arthritis
}

\author{
Y. YODFAT, Z. YOSSIPOVITCH, I. COHEN, AND E. SHAPIRA \\ From the 'Shimshon' Medical Center, Kupat Holim Beit Shemesh, and the Department of Medicine 'A', \\ Orthopedics, Immunology, and Pediatrics and Child Health, The Hadassah University Hospital, Jerusalem, Israel
}

The aetiology of juvenile rheumatoid arthritis (JRA) is unknown. All epidemiological attempts to prove a genetic background or familial predisposition were inconclusive. The three recent studies of monozygotic twins (Baum and Fink, 1968; Meyerowitz, Jacox, and Hess, 1968; Kapusta, Metrakos, Pinsky, Shugar, and Naimark, 1969), give little support for any significant genetic predisposition. According to Toumbis, Franklin, McEwen, and Kuttner (1963), serological tests showed a high prevalence of the rheumatoid factor in one pedigree. Other authors (Ansell, Bywaters, and Lawrence, 1962; Stecher, Hersh, Solomon, and Wolpaw, 1953; Hölsti and Huuskonen, 1938), demonstrated a high incidence of rheumatoid arthritis among patients' relatives. An indirect evidence for genetic predisposition was suggested by Howard and Ansell (1964), who found a higher incidence of serum haptoglobin 1-1 in children with JRA. These findings could not be confirmed by Peacock and Alepa (1966).

In the present study a family is described in which the incidence of JRA was demonstrated in five out of seven siblings, the parents being distantly related.

\section{Case reports}

Case 1, a 14-year-old boy, showed the first symptoms of the disease at the age of 3 years, with pains in the left knee, later migrating to the left hip and right knee. The pains were usually accompanied by swelling of the joints, mainly in the evening, and fever up to $39^{\circ} \mathrm{C}$. Each attack lasted at least 2 to 3 months with maculopapular non-pruritic eruption of the trunk and extremities. Between attacks, the boy felt well.

No other physical sign was found and skeletal $x$ ray examination revealed no abnormalities.

Laboratory data during an attack were as follows: erythrocyte sedimentation rate $60 \mathrm{~mm}$. $/ 1 \mathrm{hr}$. (Westegren); white blood count 11,200; antistreptolysin-O titre (AST) 125-333; C-reactive protein (CRP) 0-5+. The WaalerRose and latex-fixation tests were negative. Serum protein electrophoresis and immunoglobulins were within normal limits. Rosette test (Bach, Delrieu, and Delbarre,

Accepted for publication August 9, 1971
1970) 8 per cent. (upper normal limit 6 per cent.); antinuclear factor test positive (no LE cells found).

During the first few years he responded well to aspirin therapy, but later needed steroid therapy in addition.

Case 2, a 12-year-old boy, first showed a swelling of the right ankle with a limitation of movement at the age of 8 years. The attacks recurred approximately twice a year with a duration of 6 to 8 weeks, accompanied by typical eruption and fever up to $38^{\circ} \mathrm{C}$.

During an attack the positive laboratory data were: erythrocyte sedimentation rate $55 \mathrm{~mm}$./1 hr.; CRP 1-2+; raised $\gamma$-globulin to $2 \mathrm{~g}$./per cent. with IgG $1,653 \mathrm{mg}$. per cent.; rosette test 8 per cent.

In every episode there was a good response to aspirin therapy.

Case 3, a 10-year-old boy, showed retardation of bone age at 18 months.

Laboratory and clinical investigations did not reveal any pathological basis for this finding, and by the time he was 3 years old he had caught up and the bone age was found within normal limits. Approximately from that age onwards, however, he started limping and could not climb stairs unless he helped himself with his hands. When 5 years old, he started to complain of pains in the right knee with no evident swelling. Hypotonia was found in the upper limbs and wasting of the trunk muscles with secondary lumbar lordosis. A diagnosis of muscular dystrophy was suggested but muscular biopsy and other laboratory tests disproved this possibility. In the following years, his motor condition improved gradually, but alternating episodes of arthritis continued, mainly in the right knee with fever of more than 6 weeks' duration. Up to the present time, skeletal $x$ rays have shown typical zygapophyseal involvement.

The positive laboratory data during attacks were: erythrocyte sedimentation rate $130 \mathrm{~mm} . / 1 \mathrm{st} \mathrm{hr}$; ; wite blood count up to 14,000; AST 500 (on only one attack); raised $\gamma$-globulin to $2 \cdot 6 \mathrm{~g}$. per cent. with IgG $1,550 \mathrm{mg}$. per cent; rosette test 14 per cent.; positive antinuclear test.

The patient responded favourably to steroid treatment only.

Case 4, 9-year-old girl, showed normal motor development until the age of $2 \frac{1}{2}$ years. From then on, the mother observed walking difficulties, mainly in the evening. Both 
motor and bone age retardation was present, together with premature epiphyseal closure. During this entire period there were pains in the left knee and ankle, with alternating appearances of swelling, local heat, and temperature elevation lasting for 6 to 10 weeks. In some attacks splenomegaly was noticed with general lymphadenopathy.

Laboratory data during attacks were: erythrocyte sedimentation rate $90 \mathrm{~mm}$./1st hr.; CRP 4+-6+; latexfixation test $1: 160$ (one attack); raised $\gamma$-globulin to $2 \cdot 5 \mathrm{~g}$. per cent. with IgG $1,675 \mathrm{mg}$. per cent.; rosette test 14 per cent.; and positive antinuclear factor.

She responded favourably to aspirin or steroid therapy.

Case 5, a 5-year-old boy, showed walking disturbances from the age of 3 years, with intermittent swelling and pains in the right knee and/or ankle usually accompanied by macular eruption and high fever lasting from 8 to 12 weeks.

$X$ rays revealed zygapophyseal involvement. The positive laboratory findings were: erythrocyte sedimentation rate $45 \mathrm{~mm}$./1st hr.; AST 250; CRP 1+-2+; raised $\gamma$-globulin $2 \cdot 1 \mathrm{~g}$. per cent. with IgG $1,350 \mathrm{~g}$. per cent.; rosette test 12 per cent.; and positive antinuclear factor.

He reacted well to aspirin therapy.

The parents and the two young siblings (aged 6 months and 3 years) are healthy with no specific complaints or findings.

\section{Discussion}

Both clinical symptoms and laboratory tests in the five siblings are compatible with monoarticular onset and oligoarthritic course of JRA (Calabro and Marchesano, 1968). The specific feature is the appearance of the disease in five out of seven children in the same family. The two children who have hitherto shown no symptoms of the disease are still very young and it is possible that the disease may develop in them later. So far as we can ascertain such a heavy incidence in one family has not hitherto been described in the literature. Our patients presented pain and swelling of the joints alternating with periods of good health. No iritis, joint contractures, anaemia, or marked leucocytosis could be demonstrated in any of them. As to the localization of the pains, they started in the knee and only later migrated to other joints. Muscular wasting was found in one child only, and growth retardation appeared only in this boy and in his sister. These findings are in accordance with the observations of Grossman, Ozoa, and Arya (1965). The most prominent feature was a high erythrocyte sedimentation rate, which lasted for years and never reverted to normal, even upon steroid treatment. Fever was found in all children, and typical rash in three, whereas splenomegaly was seen only occasionally in one. Three children showed characteristic $x$ ray changes.

Although specific rheumatoid factor tests determine the positive diagnosis of adult rheumatoid arthritis, when applied to JRA, they usually give negative results (Sievers, Ahovonen, Aho, and Wagner, 1963; Friis-Hansen and Johansen, 1964). An interesting observation was the strongly positive rosette test in three children (12-14 per cent.) and the positive test in the fourth ( 8 per cent.). There is a correlation between the strongly positive rosette test and the finding of an antinuclear factor in the same four patients. Another interesting feature is the raised level of $\gamma$-globulin and IgG in some of the subjects.

The present study corroborates the assumption that genetic factors may play a part in the aetiology of the disease. With the development of further techniques for the detection of rheumatoid factors (i.e. the rosette test), it will presumably be possible to check its presence in families with JRA and thus to detect latent cases of this disease.

\section{Summary}

A family is described in which five out of seven siblings had juvenile rheumatoid arthritis. The disease presented with a monoarticular onset and an oligoarthritic course, with repeated attacks, lasting for years. All the patients showed a high erythrocyte sedimentation rate. Raised $\gamma$-globulin, high IgG, positive antinuclear factor, and positive rosette tests were demonstrated in the affected siblings.

The cumulative incidence of the disease in five members of the same family would justify the assumption of a familial predisposition, perhaps genetically determined, in the aetiology of juvenile rheumatoid arthritis.

\section{References}

Ansell, B. M., Bywaters, E. G. L., And Lawrence, J. S. (1962) Ann. rheum. Dis., 21,243 (A family study on Still's disease)

Bach, J. F., Delrieu, F., And Delbarre, F. (1970) Amer. J. Med., 49, 213 (The rheumatoid rosette; a diagnostic test unifying seropositive and seronegative rheumatoid arthritis)

BAum, J., AND FInK, C. (1968) Arthr. and Rheum., 11, 33 (Juvenile rheumatoid arthritis in monozygotic twins: A case report and review of the literature)

Calabro, J. J., and Marchesano, J. M. (1968) Med. Clin. N. Amer., 52, 567 (The early natural history of juvenile rheumatoid arthritis)

Frits-HAnsen, B., AND Johansen, P. E. (1964) Acta rheum. scand., 10, 262 (Laboratory tests in juvenile rheumatoid arthritis) 
Grossman, B. J., OzoA, N. F., ANd Arya, S. C. (1965) Med. Clin. N. Amer., 49, 33 (Problems in juvenile rheumatoid arthritis)

Hölsti, Ö., AND HuUsKonen, A. J. (1938) Acta med. scand., Suppl. 89, p. 128 (Heredofamilial arthritis. A study of four generations of an arthritis family)

Howard, A., AND ANSELl, B. M. (1964) Ann. rheum. Dis., 23, 232 (Vertical starch-gel electrophoresis in some rheumatic diseases)

Kapusta, M. A., Metrakos, J. D., Pinsky, L., Shugar, J. L., And Naimark, A. P. (1969) Arthr. and Rheum., 12, 411 (Juvenile rheumatoid arthritis in a mother and her identical twin sons)

MeYerowitz, S., JACox, R. F., AND Hess, D. M. (1968) Ibid., 11, 1 (Monozygotic twins discordant for rheumatoid arthritis: A genetic, clinical and psychological study of eight sets)

Peacock, A. C., AND AlePa, F. P. (1966) Ann. rheum. Dis., 25, 567 (Haptoglobin types in patients with juvenile rheumatoid arthritis)

Sievers, K., Ahvonen, P., Aho, K., AND Wagner, O. (1963) Rheumatism, 19, 88 (Serological patterns in juvenile rheumatoid arthritis)

Stecher, R. M., Hersh, A. H., Solomon, W. M. and Wolpaw, R. (1953) Amer. J. hum. Genet., 5, 118 (The genetics of rheumatoid arthritis: Analysis of 224 families)

Toumbis, A., Franklin, E. C., McEwen, C., And Kuttner, A. G. (1963) J. Pediat., 62, 463 (Clinical and serological observations in patients with juvenile rheumatoid arthritis and their relatives) 